\title{
Application of Sensitized Silver Nanoparticles on Pretreated Polyester and Silk Fabrics with Eco-friendly Mixed Gas Plasma
}

\author{
S.F. Ibrahim ${ }^{1 *}$, D.M. Essa ${ }^{1}$, Khaled Elnagar ${ }^{1}$, Ahmed M. Abdel-Razik ${ }^{1}$, Adel A.-H Abdel-Rahman ${ }^{2}$ \& Mohamed Saudi $^{3}$

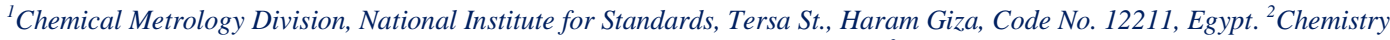 \\ Department, Faculty of Science, Menoufia University, Shebin El-Koam, Egypt. ${ }^{3}$ Physics Department, Faculty of Science, Ain Shams \\ University, Egypt. Corresponding author email: drsaherfawzy09@ hotmail.com $^{l^{*}}$
}

Copyright: @ 2021 S.F. Ibrahim et al. This is an open access article distributed under the terms of the Creative Commons Attribution License, which permits unrestricted use, distribution, and reproduction in any medium, provided the original author and source are credited.

This article studies the effect of surface modification of polyester (PET) and silk fabrics by exposing to cold plasma discharge. The cold plasma discharge was proceeded using oxygen/Argon mixed gas as a working gas and different plasma device parameters have been studied such as different time, different current and different hydrostatic pressure. Treated fabrics are characterized by the measurements and evaluation of mechanical properties, air permeability, Electron Spin Resonance (ESR) and the changes in surface morphological of pretreated fabrics were characterized by Scanning Electron Microscope (SEM) and Energy Dispersive X-Ray Analysis (EDX)). Then the exposed plasma fabrics at optimum conditions were modified with prepared nano-silver. The antibacterial activity for treated fabrics against gram positive bacteria (Staphylococcu. aurous) and gram negative bacteria (Escherichia coli) were examined. Also the ultraviolet protection factor (UPF) values increase for both exposed fabrics but the increase is not significant in silk fabrics while antibacterial properties were highly improved by the treatment of fabric. As an applied part for the efficiency of the plasma and nano-treatment, oxygen and oxygen/argon mixed gas plasma and/or nano-silver treated silk samples were separately dyed with Natural Red Lac Dye. Finally, as a metrological part, the uncertainty budget of tensile strength measurement of polyester samples was calculated and analyzed with a well verified traceability via applying all the measurements which are traceable to SI units.

Keywords: Antibacterial properties, DC plasma discharge, ESR, Mechanical properties, Mixed oxygen, Polyester and silk.

\section{Introduction}

The term plasma was first used by Irving Langmuir and describes quasi-neutral ionized or partially ionized gas in electric discharge. The plasma consists of variety of particles, neutral atoms and molecules, charged particles (electrons and ions), metastable particles (excited atoms and molecules, radicals) and photons [1]. Depending on temperature of particles, plasma can be classified into two categories: equilibrium or thermal plasma and non-equilibrium or non-thermal plasma. The thermal plasma is characterized by an almost completely ionized gas and high temperature of at least $15,000 \mathrm{~K}$. The non-thermal or cold plasma is a partially ionized gas with temperature generally close to room temperature (maximum $340 \mathrm{~K}$ ) [2].

Natural dyes have been used in the dyeing of natural fibers such as wool, cotton, silk, fur, and leather from prehistoric times to the nineteenth century [3]. Natural dyes are obtained from naturally occurring sources such as plants, insects, and minerals with or without minimal chemical treatment and cause less environmental and wastewater problems Compared to some synthetic dyes, they are more environmentally eco-friendly [4].

The worldwide demand for natural dyes is gaining great attention these days due to the increasing awareness of environmental importance and a wide range of applications such as engineering, food, textile, medical, and agricultural industries [5]. Natural flavonoids and anthraquinones constitute two important groups of dyestuffs. Flavonoids and anthraquinones have the ability to make complexes with metals. Weld Reseda luteola L. is the most abundant natural yellow and the component of green dyes in the world [6]. It contains flavonoid dyes named luteolin and apigenin, luteolin-7-glucoside, and luteolin-3,7 di-O-glucoside are presented as the three main flavonoids of weld [7]. Lac dye (CI Natural Red 25; CI 75450) is obtained from an insect Coccus laccae (Laccifer 
lacca Kerr), found on the twigs of certain tree native to Southeast Asia. The insect produces a resin known as stick lac.1 Lac dye or laccaic acid has two major compositions: laccaic acid A and B where, Lac is the parent of modern plastics and the importance of lac in the modern economy, is quite considerable [2]. Lac dye is a red colored natural dye, which is present in the body fluid of lac insect, known as Laccifer lacca. This dye is a byproduct of lac industry which is generally lost during washing of sticklac in primary processing of lac [8]. A pretreatment is required to dye the textile fiber with natural dyes [9]. The process of binding metals or materials to textile fibers is called mordanting, and the materials used for this purpose are called mordant substances [10]. Water-soluble metal salts are used as mordant substances, as well as substances with weak acid or base properties [11]. Flavonoids and anthraquinones form complexes with metals are effective metal chelates. Weld has been used to dye both animal fibers and vegetable fibers, after they have been treated with mordant substances [12].

This study aims to evaluate the effect of applying silver nanoparticles in treatments of polyester and silk fabrics after eco-friendly mixed gas plasma surface activation using oxygen/ argon mixed gas as a working gas and different plasma device parameters have been studied such as: different time, different current and different hydrostatic pressure. As an applied part for the efficiency of the plasma and nano-treatment, Oxygen/argon mixed gas plasma treated silk samples were separately dyed using the conventional dyeing method. Finally, as a metrological part, uncertainty budget of tensile strength measurement of polyester samples was calculated.

\section{Experimental Work}

\subsection{Materials and chemicals}

1- Polyester fabrics $108 \mathrm{~g} / \mathrm{m}^{2}$ is provided by "OUF" son's Company, Cairo. Yarn counts of the fabric were 24 in the warp yarn and 18 in the weft.

2- Silk fabrics $65 \mathrm{~g} / \mathrm{m}^{2}$ is provided by Central Silk Board, India.

3- Non-ionic detergent, sodium carbonate, Alum power, acetone, sodium hydroxide, 4-Hydroxyethyl cellulose (HEC), Silver nitrate with assay of $99 \%$ produced by Aldrich Company.

\subsection{Dye Stuff}

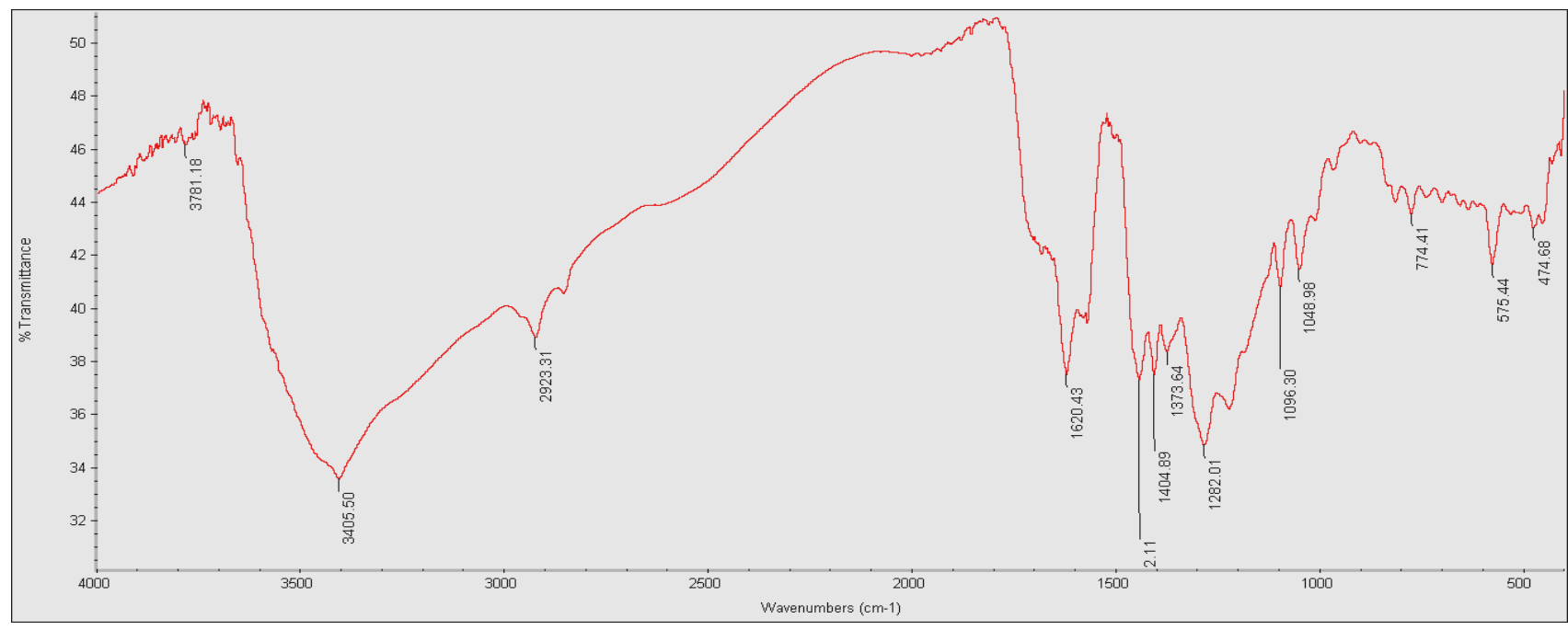

Fig.1. The infrared (IR) spectrum of the extracted Lac dye 
Natural Red lac Dye (Natural Red 25) was obtained from Central Silk Board, India and Fig.1 shows the infrared (IR) spectrum of the extracted Lac dye.

\subsection{Plasma Production}

The schematic diagram of the experimental set-up of exposing samples surface to oxygen plasma or oxygen argon mixed gases plasma was last mention in our previous works $[13,14]$. The samples were treated with oxygen plasma or oxygen/argon mixed gases plasma at different conditions of pressure, current, and time. The working pressures used for treatment of samples are: 0.2, 0.3, 0.4 torr. The discharge current applied for each samples is ranged from 30 to $55 \mathrm{~mA}$. The exposure time for each sample is ranged from 15 second to 2 minutes.

\subsection{Synthesis of nano- silver particles}

The nano- silver particles were synthesized according to green synthesis method of silver nano particles which was characterized by Zeta Potential and particle size determination, Transmission electron microscope (TEM) and UV/Visible Spectral Analysis. The characterization of the synthetized nanosilver with the desired properties was approved in our previous work $[13,14]$.

\subsection{Application of synthesis nano- silver on exposed fabrics [15, 16]}

All Oxygen/ Argon mixed plasma treated polyester and silk samples at optimum conditions were separately treated with nano-silver metal. We should shack nano-silver colloidal solutions by using magnetic stirrer for homogeneity before each treatment, then plasma treated samples were dipping and stirred in nano-silver colloidal solutions. After that treated fabrics were dried at room temperature without rinsing.

\subsection{Dyeing of Treated Silk Fabric}

Oxygen/argon mixed gas plasma treated silk samples were separately dyed using the conventional dyeing method (17), with liquor ratio (1:50), Silk samples dyed separately with Red lac Natural Red 25; CI 75450 using 0.1 g/L alum as mordant.

\subsection{Characterization of treated samples}

\subsubsection{Air Permeability}

All treated and untreated samples of polyester and silk were tested for their air permeability using SDL Air permeability tester, England. The measurements were carried out according to the standard method [19].

\subsubsection{Mechanical Measurements}

All treated and untreated samples of polyester and silk were tested for their tensile strength and elongation behaviors using a Shimadzu Universal Tester of (C.R.T) type S-500, Japan. The results listed in this paper are the mean of five times measurements [20].

\subsubsection{Electron Spin Resonance Spectroscopy (ESR)}

The ESR spectra of blank (untreated polyester and silk) and plasma treated fabric samples under the effect of different treatment conditions of time, pressure and current were recorded using an X-band ESR spectrometer 
(Bruker, EMX) at room temperature using high sensitivity standard cylindrical cavity (ER4119HS) operating at 9.7 $\mathrm{GHz}$ with a $100 \mathrm{kHz}$ modulation frequency [20, 21].

\subsection{4. $U$ V protective factor $(U P F)$}

The UPF (ultraviolet protection factor) is a numerical rating given to clothing to indicate how effectively the fabric blocks ultraviolet (UV) radiation.

The transmittance and UPF values of the examined fabric samples were measured using a Varian (UV-VIS-NIR) spectrophotometer according to the reported standard test method (AS/NZS 4399, Sun protective clothing-evaluation and classification [22]. The tested samples were classified according to their UPF values: $<15$ Poor, 15 to 24 Good, 25-39 Very Good, > 39 Excellent [23].

\subsection{Characterization of Plasma Treated Polyester and Silk Samples at Optimum Conditions}

Treated polyester and silk samples exposed to plasma at the optimum conditions for each factor including, time, pressure and current are subjected to the following testes;

\subsubsection{Scanning Electron Microscope (SEM) [24]}

Surface morphological changes of blank untreated and those plasma treated fabric samples with oxygen/argon mixed gas were determined using Scanning Electron Microscope (SEM) Model Quanta 250 FEG (Field Emission Gun) and the treated plasma exposed polyester and silk samples at optimum Conditions with nano-silver in the attached EDX Unit (Energy Dispersive X-ray Analyses), with accelerating voltage $30 \mathrm{~K}$.V., magnification14x up to 1000000 and resolution for Gun.1n) in The Egyptian Mineral Resources Authority Central Laboratories Sector.

\subsubsection{Antibacterial Properties}

Antibacterial behaviors of blank, plasma exposed and nano-silver treated samples were evaluated according to the standard method [25], Antibacterial activity Assessment of Textile Material: parallel streak Method).

The Antibacterial properties of the fabric samples $(1 \mathrm{~cm}$ diameter $)$ were investigated by incubating bacteria solutions of both Staphylococcus aureus (Gram-positive) and Escherichia coli (Gram-negative) at $37^{\circ} \mathrm{C}$ for $18-24$ hours.

\subsection{Dyeing Properties of the Plasma Pretreated Silk Fabric samples}

\subsubsection{Color Strength and Color Difference [26]}

The color strength $(\mathrm{K} / \mathrm{S})$ values and color difference $(\Delta \mathrm{E})$ of treated dyed samples were determined using a SDL Optimatch Color Matching System, England.

\subsubsection{Fastness Properties}

The fastness properties to washing were determined according to standard method [27], the washing fastness grade was assessed using standard Gray Scale which ranges from (1-5), where 5 (excellent), 4 (good), 3 (fair), 2 (poor) and 1 (very poor). While, the staining 5 (no staining), 4 (slightly staining), 3 (noticeable staining), 2 (considerable staining) and 1(heavy staining). The fastness to light was performed using Tera Light Fastness Tester in the textile 
metrology lab, at the National institute of standards. Where, the different examined dyed samples are exposed to artificial day light for 40 hours then light fastness values are assessed visually based on standard test method [28].

\section{Results and Discussion}

\subsection{Optimization of Plasma Treatment of Silk and Polyester Fabrics using Oxygen/Argon Mixed Gas}

The textile samples were exposed to pseudo plasma discharged of power ranging from 1-20 W. The textile sample of $7.5 \mathrm{~cm}$ diameter was placed in front of the mesh anode at an axial distance $\mathrm{Z}=6 \mathrm{~cm}$ from the mesh. The samples were studied under different conditions of time, pressure and current. The effect of different exposure conditions on air permeability, mechanical properties, UV protective factor (UPF) and electron spin resonance spectroscopy (ESR) results are discussed as follows:

\subsubsection{The Effect of Different Exposure Time on Silk and Polyester Fabrics}

Silk and Polyester fabrics were exposed to pseudo plasma using oxygen/ argon mixed gas at different exposure time intervals (15-30-45-60-90-120) sec at Current $45 \mathrm{~mA}$ and Pressure 0.3 Torr.

\subsubsection{UV Protective Factor (UPF)}

Table 1 shows the results of UPF values of different exposure time on silk and Polyester treated fabrics. We notice that the UPF values has no significant for silk fabrics, while for polyester fabrics it increases by increasing the exposure time, it reaches from (14.15) poor protection for blank to (38.65) very good protection. The natural fibers like silk have lower degree ultra violet protection than synthetic fibers such as polyester fabrics [29].

\subsubsection{Air Permeability}

The results in table 1 illustrated the air permeability for the treated silk and PET fabrics at different exposure time. We found that for silk fabrics the air permeability increase by increasing of exposure time but for polyester fabrics the air permeability increase in the time range from $15 \mathrm{sec}$. up to $30 \mathrm{sec}$. that may be related to the formation of new pores due to surface etching that occurs by oxygen plasma treatment. so the porosity increase of the plasma treated PET and silk samples [30], then start to decrease in the time range from $45 \mathrm{sec}$. to $120 \mathrm{sec}$, for PET fabrics this may be due to the possibility of saturation to occur at extended time which may results in two competing processes-binding of oxygen atoms to the surface and breaking up of polymer chains to result in the production of low molecular weight fragments [31].

\subsubsection{Tensile Strength}

The results of tensile strength for the treated silk and PET fabrics at different exposure time are shown in table 1. For silk fabrics, the tensile strength increases up to 30 secs and then slightly decrease, it may be due to the oxidation effect of oxygen plasma on silk fibers which can cause the reduction of the tensile strength.

However, the maximum loss in tenacity was $(2.21 \%)$ for samples treated with oxygen/argon mixed gas. This maximum reduction in strength is still in the acceptable range. The results of tensile properties measurements confirm that plasma treatments can be used on silk yarn without significant adverse effect on the physical properties of the fibers, especially when applied at durations up to (30) sec [32]. While for polyester fabrics, it 
increases up to 30 secs this is due to increase the amorphosity of treated fabric samples by plasma exposure then decrease gradually by continuous exposure time, which may be due to the thermal effect of this treatment on fabric structure of the exposed polyester fabrics [33].

Table 1. The effect different exposure time on silk and PET treated fabrics

\begin{tabular}{|c|c|c|c|c|c|c|}
\hline \multirow{2}{*}{$\begin{array}{c}\text { Time } \\
(\mathbf{s e c})\end{array}$} & \multicolumn{2}{|c|}{ UPF } & \multicolumn{2}{c|}{$\begin{array}{c}\text { Air permeability } \\
\left(\mathbf{c m}^{3} / \mathbf{c m} / \mathbf{S}\right)\end{array}$} & \multicolumn{2}{c|}{$\begin{array}{c}\text { Tensile strength } \\
\text { (Kgf) }\end{array}$} \\
\cline { 2 - 7 } & Silk & PET & Silk & PET & Silk & PET \\
\hline Blank & 4.45 & 14.15 & 30.61 & 9.82 & 67.80 & 102.76 \\
\hline 15 & 4.64 & 14.66 & 32.45 & 12.39 & 66.60 & 107.30 \\
\hline 30 & 6.76 & 15.44 & 36.15 & 15.65 & 66.01 & 115.00 \\
\hline 45 & 4.08 & 13.33 & 36.45 & 12.25 & 64.50 & 105.20 \\
\hline 60 & 4.44 & 12.77 & 36.66 & 11.23 & 64.80 & 109.90 \\
\hline 90 & 4.60 & 14.75 & 36.84 & 10.33 & 61.30 & 110.90 \\
\hline 120 & 5.41 & 16.42 & 37.15 & 8.63 & 57.30 & 112.30 \\
\hline
\end{tabular}

\subsubsection{The Effect of Different Plasma Exposure Current on Silk and PET Fabrics}

Silk and PET fabrics were exposed to pseudo plasma using oxygen/argon mixed gas at different plasma exposed current (30, 45, 55 m.A.) at Pressure 0.3 torr and exposure time $30 \mathrm{sec}$.

\subsubsection{1. $U$ V protective factor (UPF)}

The results in table 2 illustrated the UPF values at different plasma exposed current for the treated silk and PET fabrics, the UPF values increase by increase the plasma exposed current for both fabrics but the increment is not effective for silk fabrics it still poor protective and slightly effect for polyester reach to 16 which it become good protective [34].

\subsubsection{Air permeability}

Table 2 shows the results of air permeability at different plasma exposed current for the treated silk and PET fabrics. We found that air permeability of treated silk fabric increase by increase current and for polyester fabrics it increase by increase current up to $45 \mathrm{~m}$.A., then it decrease with an increasing by a percent of (15\%) for oxygen/argon mixed plasma. This result is due to the increase in the porosity of the plasma treated polyester sample these results verified the effect of plasma exposure on decreasing the strength of the irradiated samples and hence their ability to pass air through its structure, resulting in increasing their air permeability values [35].

\subsubsection{Tensile Strength}

The result of tensile strength for the treated silk and PET fabrics at different plasma exposed current shown in table

2. The tensile strength for treated silk fabric increase by increase current up to 45 m.A., then it decreases while for 
treated polyester fabrics it increase by increase current. These results clarify that increasing on the plasma applied current the fabric melted by the thermal effect of plasma to the extent that results in the compactness and crystallinity of the fabrics and hence increasing of the tensile strength values of those pretreated samples [32]

Table 2. The effect different plasma exposed current on silk and PET treated fabrics

\begin{tabular}{|c|c|c|c|c|c|c|}
\hline \multirow{2}{*}{$\begin{array}{c}\text { Current } \\
\text { (m.A.) }\end{array}$} & \multicolumn{2}{|c|}{ UPF } & \multicolumn{2}{c|}{$\begin{array}{c}\text { Air permeability } \\
\left(\mathbf{c m}^{3} / \mathbf{c m} / \mathbf{S}\right)\end{array}$} & \multicolumn{2}{c|}{$\begin{array}{c}\text { Tensile strength } \\
\text { (Kgf) }\end{array}$} \\
\cline { 2 - 7 } & Silk & PET & Silk & PET & Silk & PET \\
\hline Blank & 4.45 & 14.15 & 30.61 & 9.82 & 67.80 & 102.76 \\
\hline 30 & 6.19 & 14.33 & 31.41 & 11.31 & 66.50 & 108.50 \\
\hline 45 & 6.76 & 15.44 & 36.15 & 15.65 & 66.01 & 115.00 \\
\hline 55 & 8.01 & 25.73 & 37.18 & 8.18 & 59.90 & 116.20 \\
\hline
\end{tabular}

\subsubsection{The Effect of Different Plasma Hydrostatic Pressure on Silk and PET Fabrics}

Silk and PET fabrics were exposed to pseudo plasma using oxygen/argon mixed gas at different plasma hydrostatic pressure (0.2, 0.3, 0.4 torr.) at current 45 m.A., and exposure time $30 \mathrm{sec}$.

\subsubsection{1. $U$ V protective factor $(U P F)$}

The results in table 3 illustrated the UPF values at different plasma hydrostatic pressure for the treated silk and PET fabrics, the UPF values increase by increase the plasma pressure for polyester it become excellent protective at 0.4 torr because the fabric melted by the thermal effect of plasma to the extent that provides increasing of the compactness and crystallinity of the fabrics which cause]decreasing in the porosity of the polyester fabric that increase the UPF whereas it reflect more UV rays, making the fabric more compact and lower transmission thus increasing UPF reaches to be very good [29], while it has no significance effect for silk fabrics it is poor protective.

\subsubsection{Air permeability}

Table 3 shows the results of air permeability at different plasma hydrostatic pressure for the treated silk and PET fabrics. As the plasma pressure increase the air permeability of treated silk fabric increase and for polyester fabrics it increases up to 0.3 torr. then it decreases this can be explained in view of the effect of pressure on energy of the charged particles leading to a large effect on the fabric surface, thus increasing their permeability in air [30, 31].

\subsubsection{Tensile Strength}

The results of tensile strength for the treated silk and PET fabrics at different plasma pressure shown in table 3. The tensile strength for both treated fabrics increase by increase plasma pressure up to 0.3 torr, then it decreases. For silk fabric it may be due to the oxidation effect of oxygen plasma on silk fibers which can cause the reduction of the tensile strength, then by increasing the plasma pressure the fabric damage by the thermal effect of plasma [32].

While for polyester fabric is due to the melting of fabric by the thermal effect of plasma to the extent that results in the compactness and crystallinity of the fabrics and hence increasing of the tensile strength values of those pretreated samples. 
Table 3. The Effect of Different plasma hydrostatic pressures on Silk and PET treated fabrics

\begin{tabular}{|c|c|c|c|c|c|c|}
\hline \multirow{2}{*}{$\begin{array}{c}\text { Pressure } \\
\text { (torr) }\end{array}$} & \multicolumn{2}{|c|}{ UPF } & \multicolumn{2}{c|}{$\begin{array}{c}\text { Air permeability } \\
\left(\mathrm{cm}^{3} / \mathrm{cm} / \mathbf{S}\right)\end{array}$} & \multicolumn{2}{c|}{$\begin{array}{c}\text { Tensile strength } \\
\text { (Kgf) }\end{array}$} \\
\cline { 2 - 7 } & Silk & PET & Silk & PET & Silk & PET \\
\hline Blank & 4.45 & 14.15 & 30.61 & 9.82 & 67.80 & 102.76 \\
\hline 0.2 & 6.09 & 14.64 & 38.24 & 8.41 & 57.50 & 112.20 \\
\hline 0.3 & 6.76 & 15.44 & 36.15 & 15.65 & 66.01 & 115.00 \\
\hline 0.4 & 11.48 & 24.44 & 31.76 & 9.84 & 66.22 & 111.00 \\
\hline
\end{tabular}

3.2. Effect of plasma exposure on Electron Spin Resonance Spectroscopy (ESR) using $\mathrm{O}_{2} / \mathrm{Ar}$ mixed gas

\subsubsection{Effect of different time}

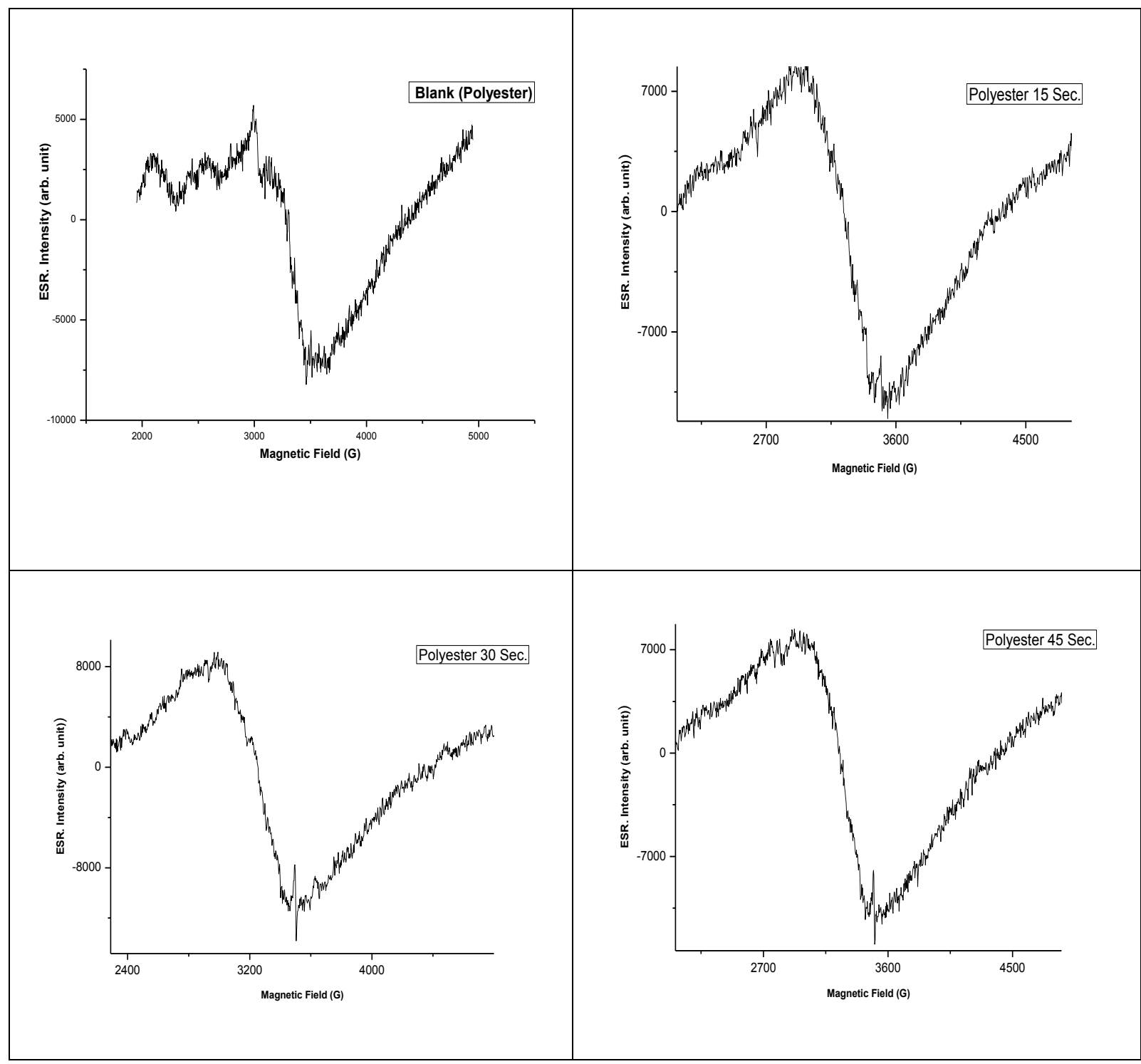




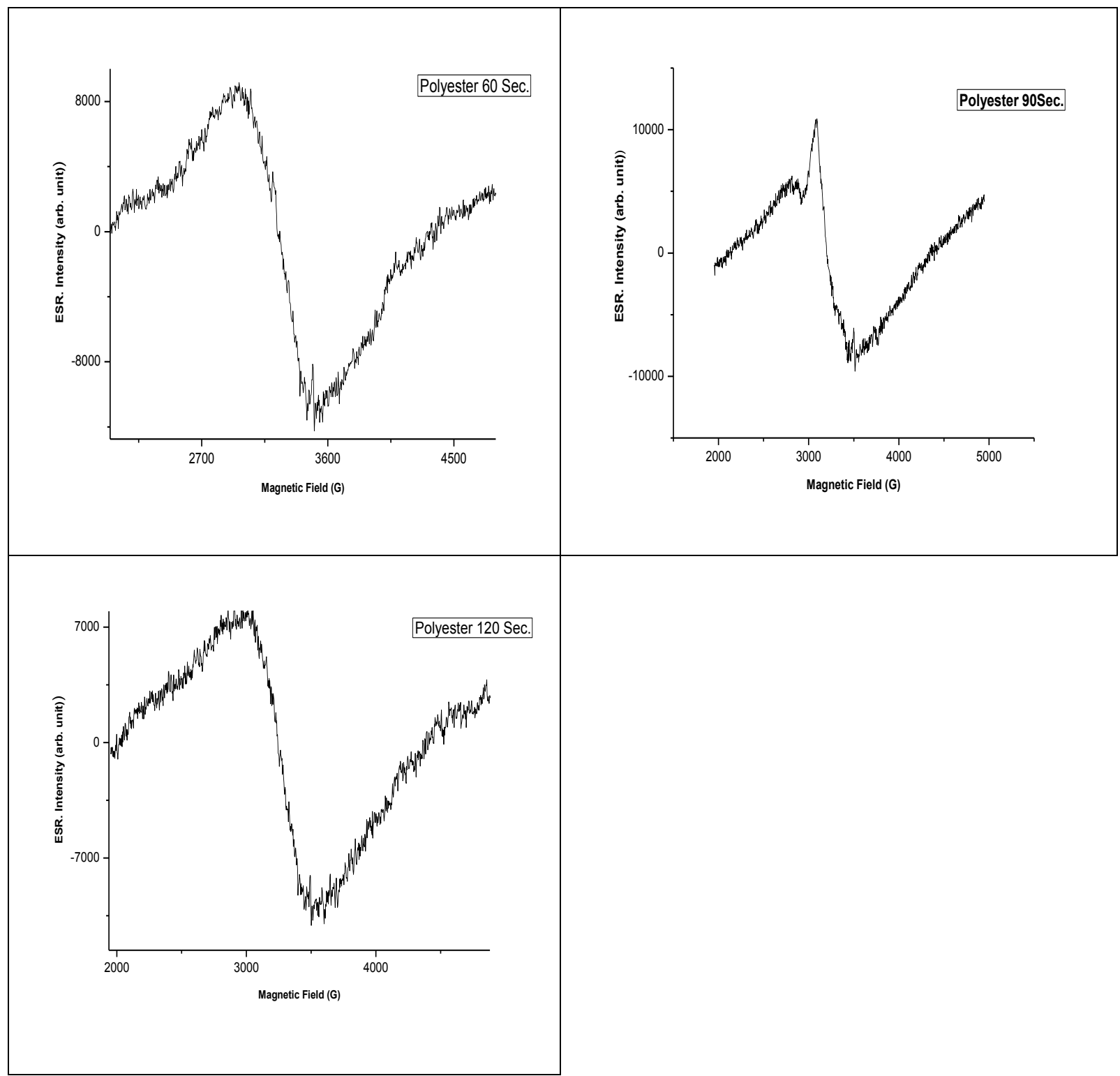

Fig.2. The change in ESR Intensity of untreated and treated polyester samples exposed to $\mathrm{O}_{2} / \mathrm{Ar}$ mixed plasma at different exposure times

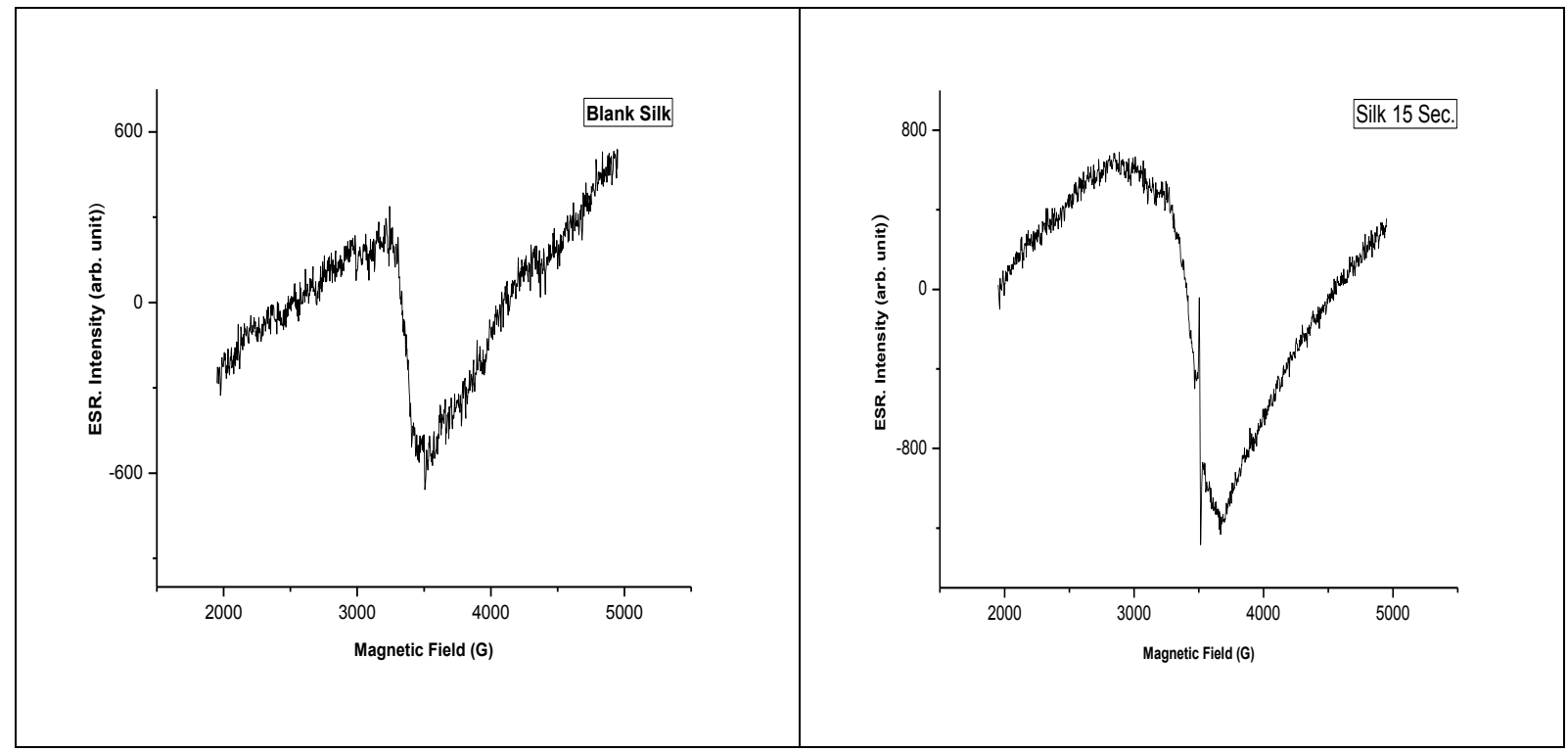




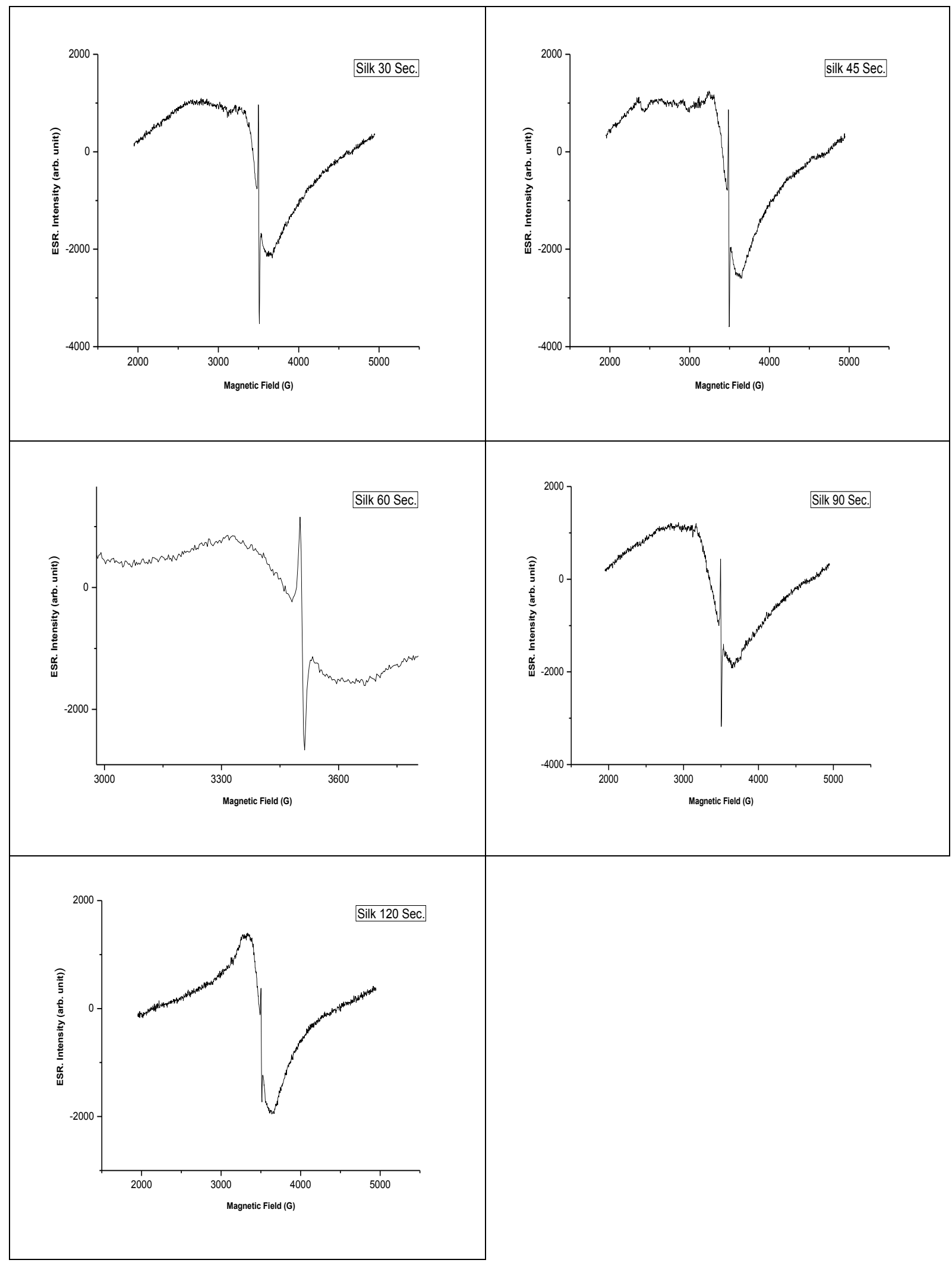

Fig.3. The change in ESR Intensity of untreated and treated silk samples exposed to $\mathrm{O}_{2} / \mathrm{Ar}$ mixed plasma

Figs.2-3 show the Change in ESR Intensity of plasma treated Polyester and silk fabrics respectively using oxygen/argon mixed gas at different times intervals (15-30-45-60-90-120 Sec.), pressure 0.3 Torr as well as the current $45 \mathrm{~mA}$. By following up of the variations in the figures we can conclude that plasma treatment of both silk and polyester samples resulted in more surface activation of them till $30 \mathrm{~s}$. 


\subsubsection{Effect of different plasma pressure}

Figs.4-5 show the change in ESR Intensity of plasma treated Polyester and silk fabrics respectively using oxygen/argon mixed gas at different plasma hydrostatic pressure $(0.2,0.3,0.4$ torr.) at current $45 \mathrm{~m} . \mathrm{A}$. and exposure time $30 \mathrm{sec}$.

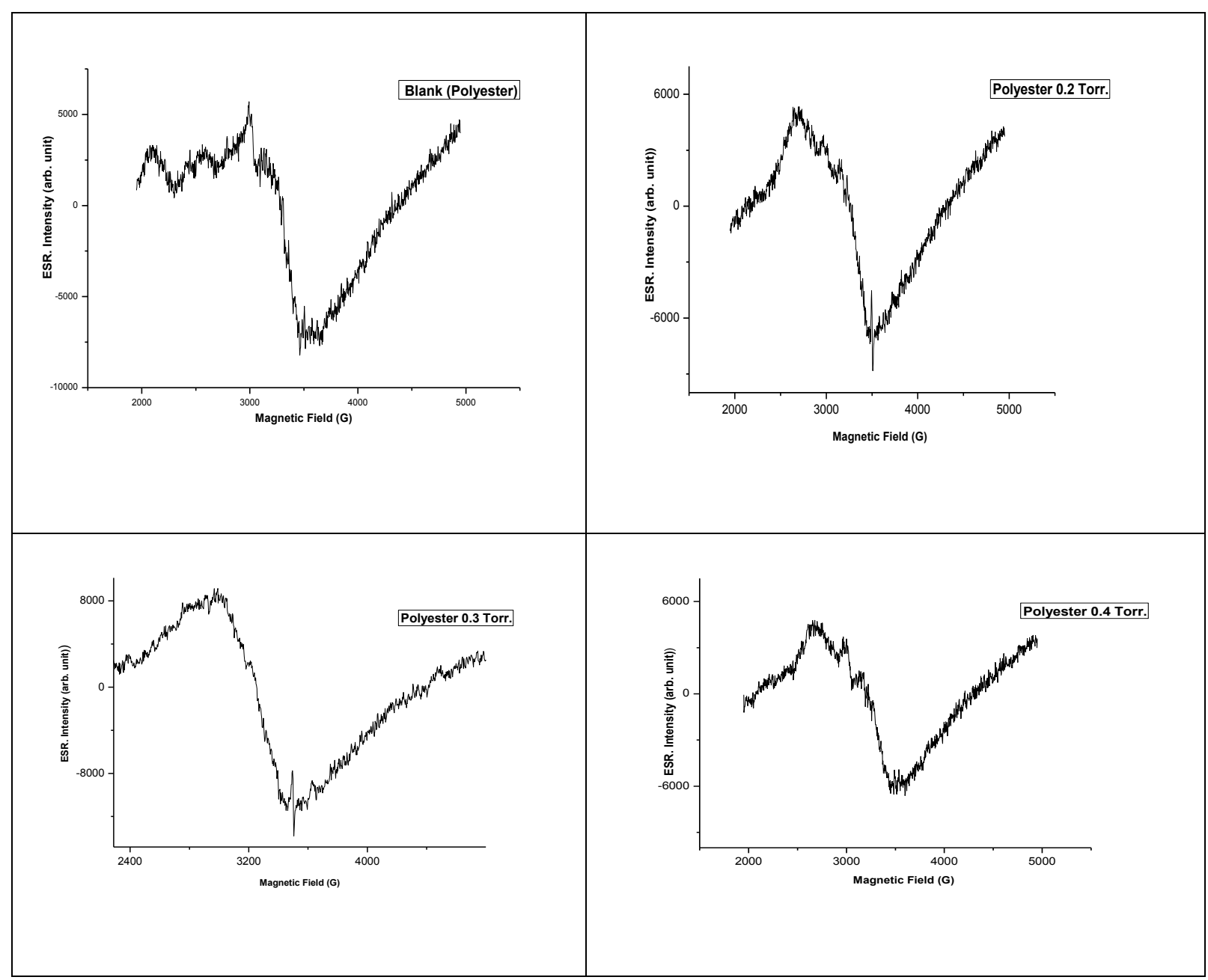

Fig.4. The change in ESR Intensity of untreated and treated polyester samples exposed to $\mathrm{O}_{2} / \mathrm{Ar}$ mixed plasma at different plasma pressure

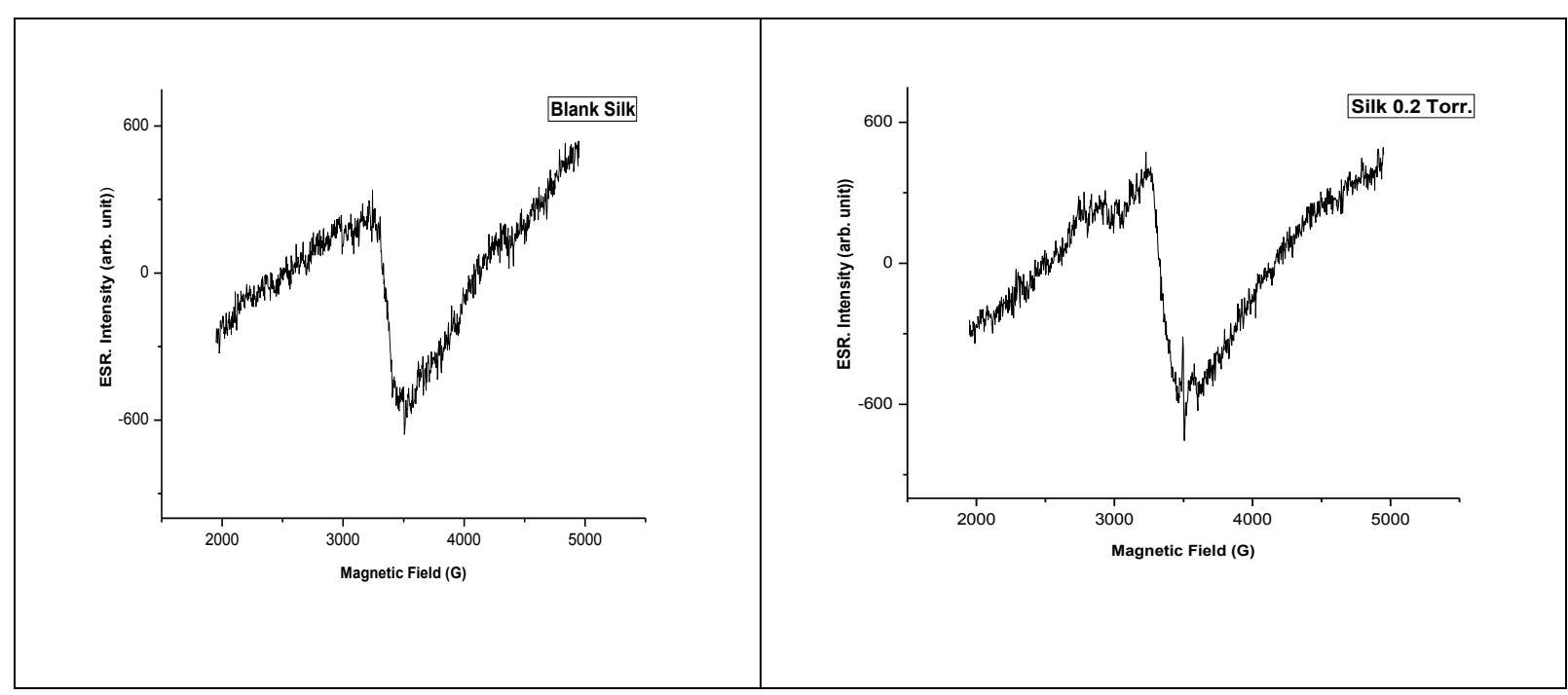




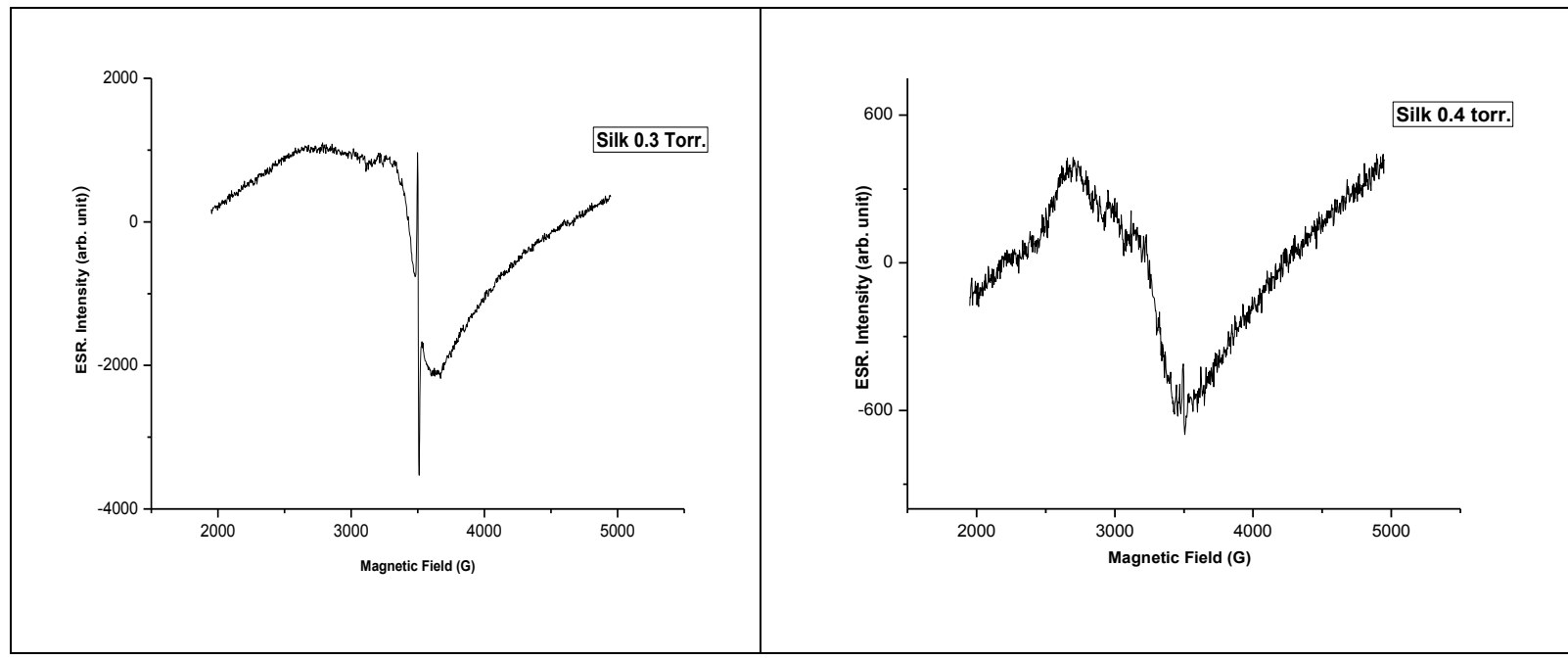

Fig.5. The change in ESR Intensity of untreated and treated silk samples exposed to $\mathrm{O}_{2} / \mathrm{Ar}$ mixed plasma at different plasma pressure

It is clear that there is an increase in peak intensity values for plasma treated silk indicating more surface activity of them up to (0.3) torr. As the same plasma treatment of polyester samples resulted in more surface activation which is influenced by increasing amplitude of pressure extending to 0.3 torr [32].

\subsubsection{Effect of different plasma current}

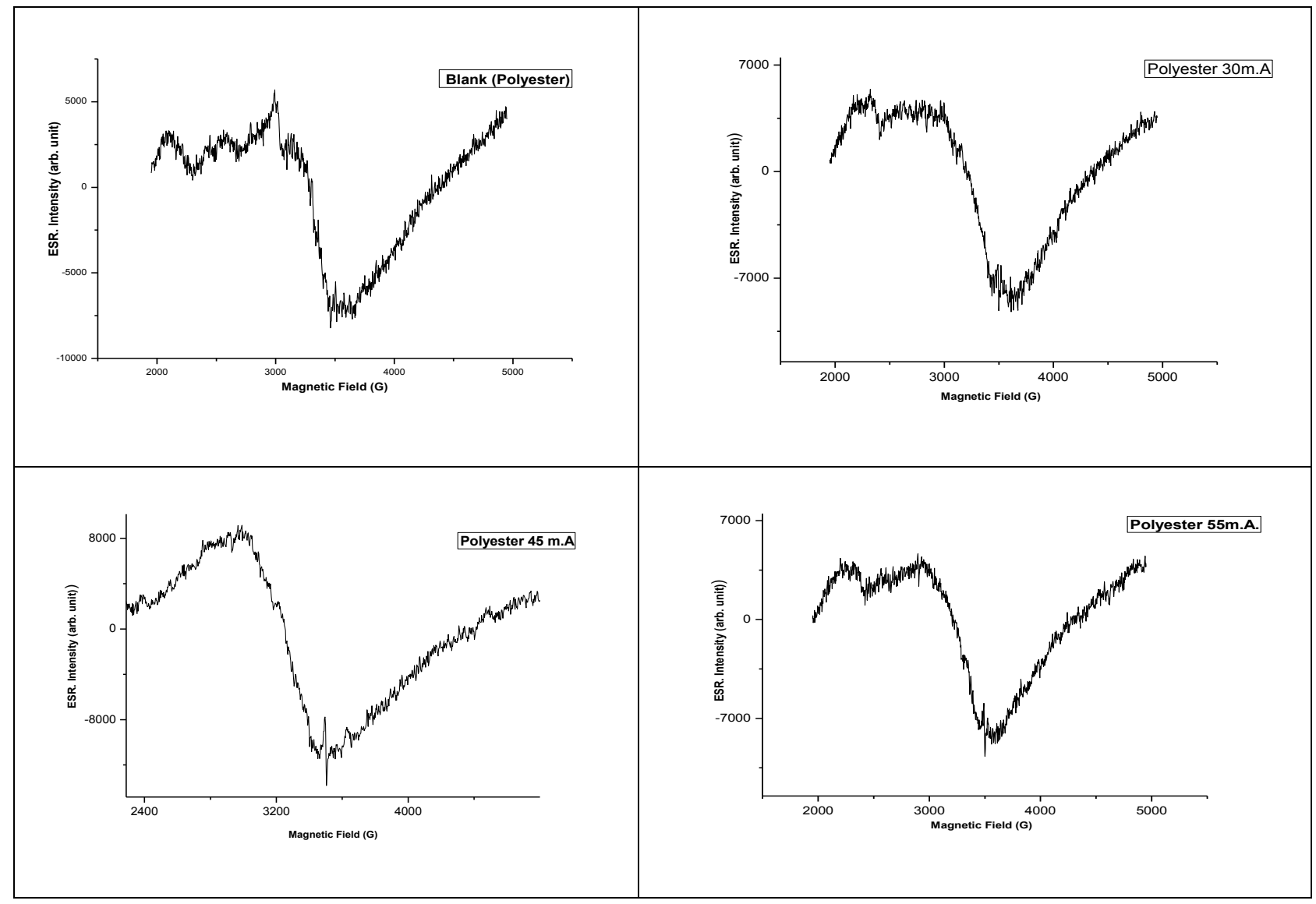

Fig.6. The change in ESR intensity of untreated and treated polyester samples exposed to $\mathrm{O}_{2} / \mathrm{Ar}$ mixed plasma at different plasma current 


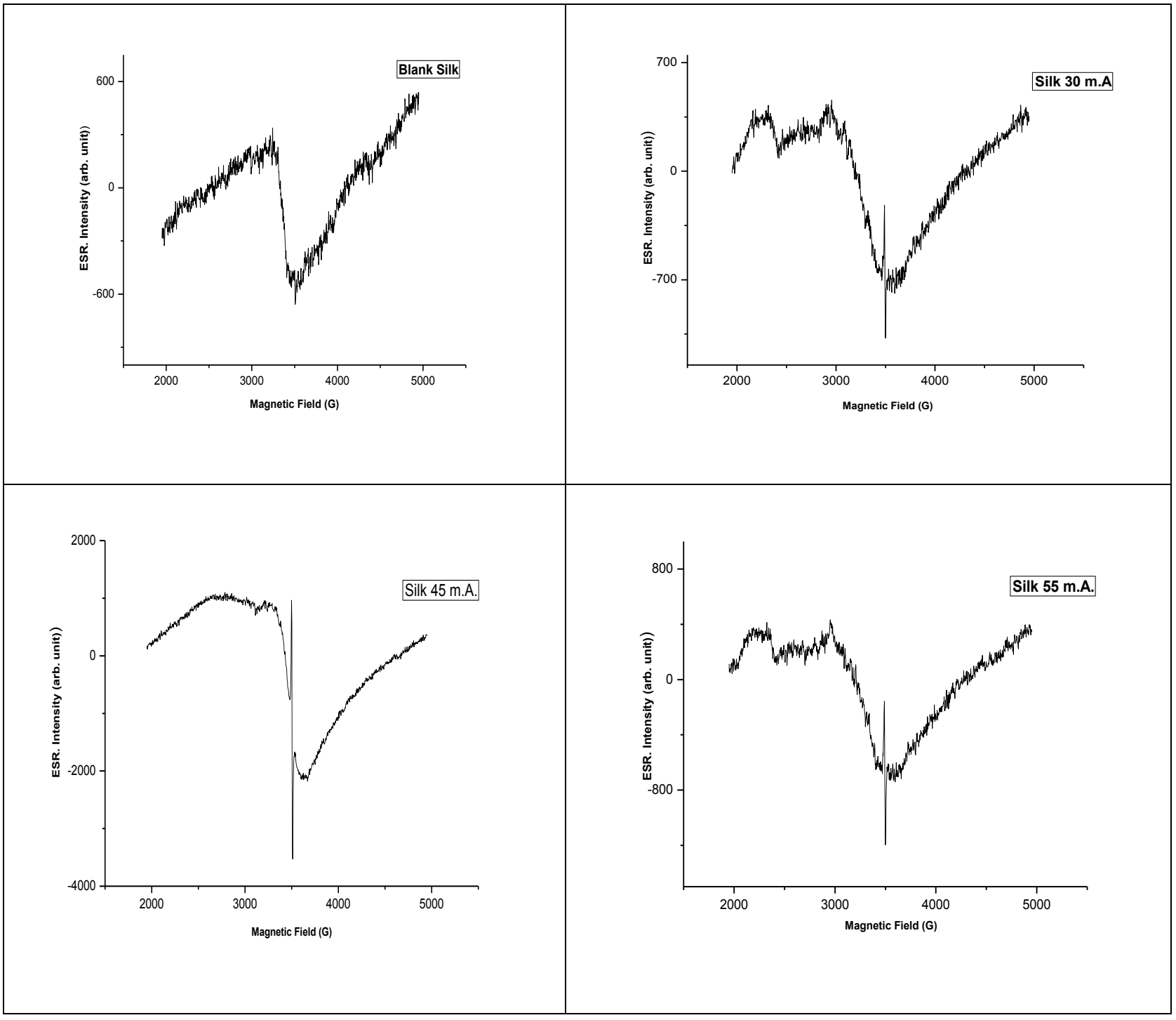

Fig.7. The change in ESR Intensity of untreated and treated silk samples exposed to O2/ Ar mixed plasma at different plasma current

Figs.6-7 show the change in ESR intensity of plasma treated polyester and silk fabrics respectively using oxygen/argon mixed gas at different plasma exposed current $(30,45,55$ m.A.) at pressure 0.3 torr and exposure time $30 \mathrm{sec}$. We can illustrate that there is an increase in peak intensity values for plasma treated silk and polyester samples indicating more surface activity of them up to $45 \mathrm{~m}$.A.

\subsection{Characterization of optimum plasma treated silk and PET samples}

\subsubsection{Scanning Electron Microscope (SEM)}

The changes in surface morphology of plasma treated polyester and silk samples in a medium of oxygen/argon mixed gas at the optimum conditions were studied by using Scanning Electron Microscope (SEM). We obtained from Figs.8 (a-f) that the untreated polyester and silk fabrics have a smooth surface relatively with little grooves, while surface morphology of the exposed polyester and silk fabrics have increase in roughness of surface due to the etching effect of plasma active species bombardment of the fiber surface [24] it is well Known that the plasma treatment of fabrics surface leads to etching, cleaning and activation of the surface. 

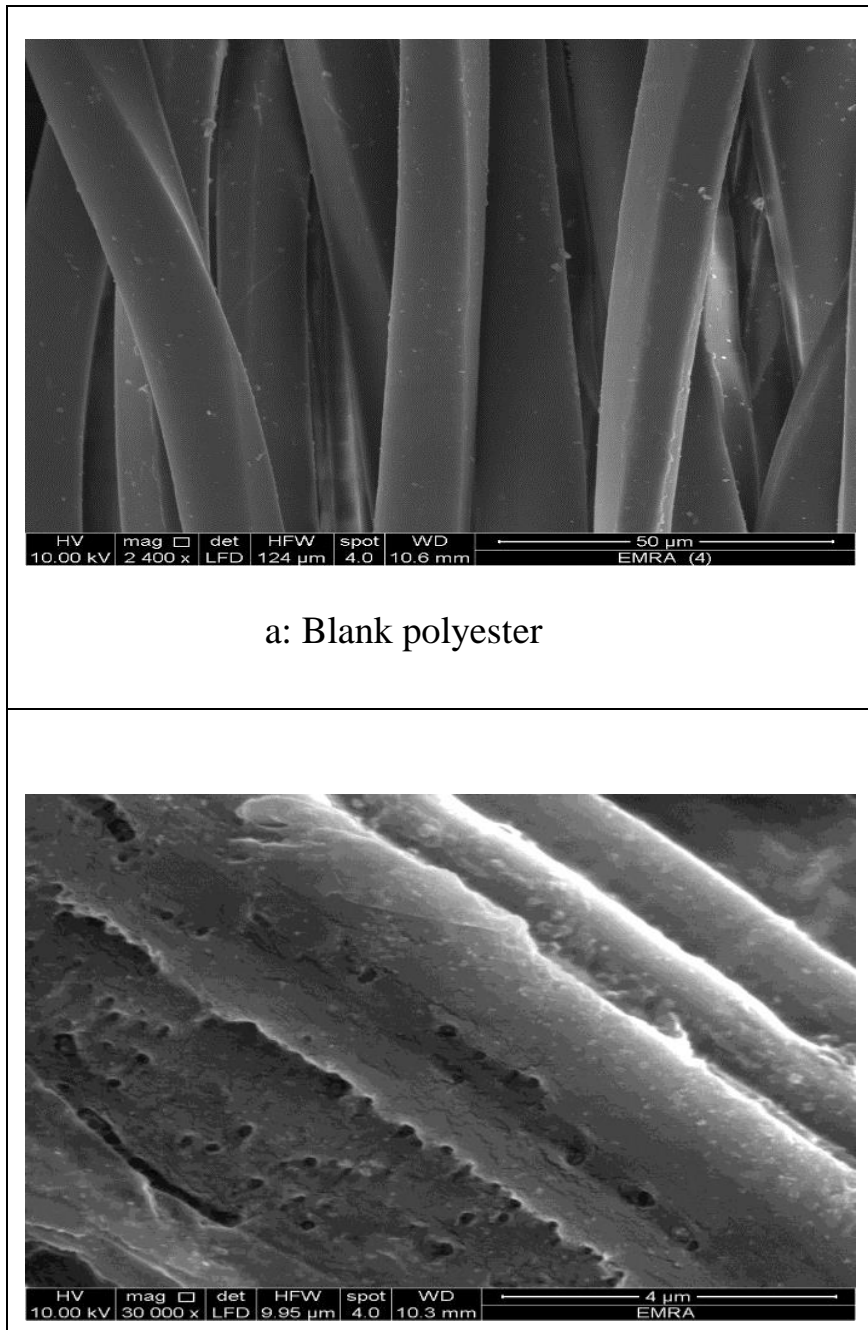

C: Polyester exposed to O2/Ar mixed plasma treated with nano-silver

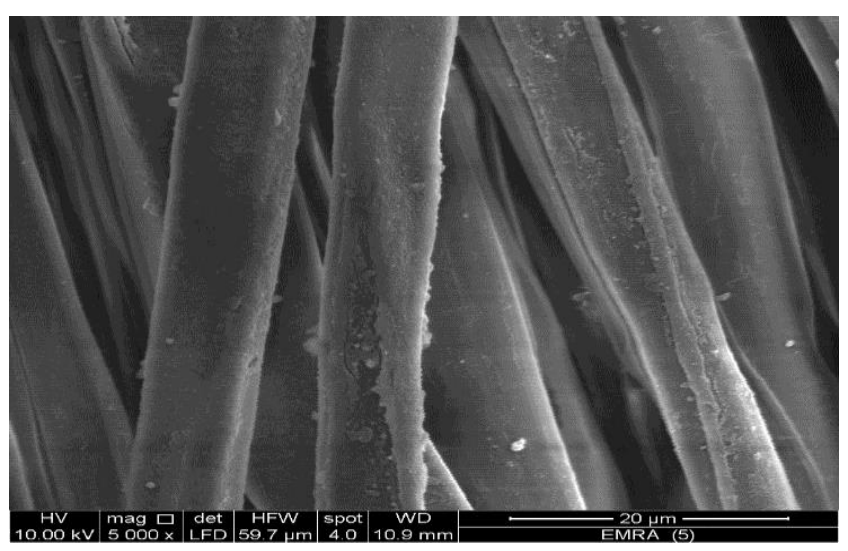

e: Silk exposed to $\mathrm{O}_{2} / \mathrm{Ar}$ mixed gas plasma

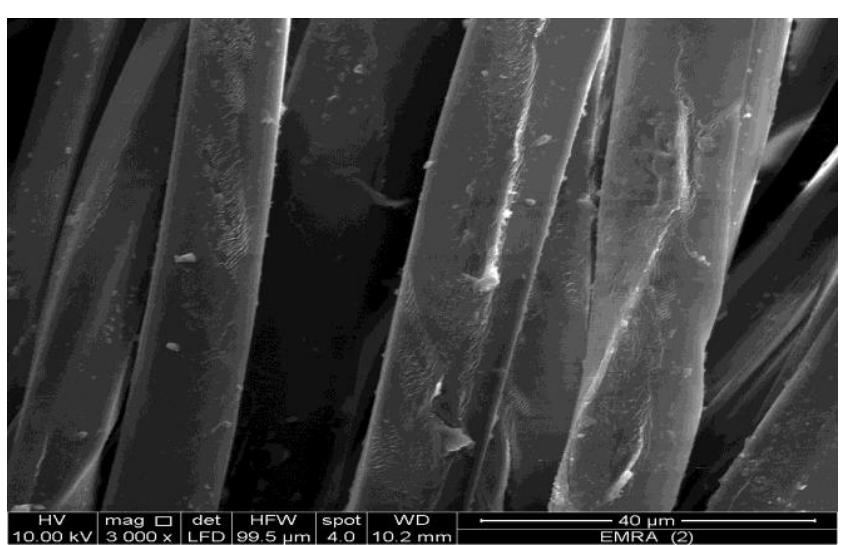

b: Polyester exposed to $\mathrm{O}_{2} / \mathrm{Ar}$ mixed plasma

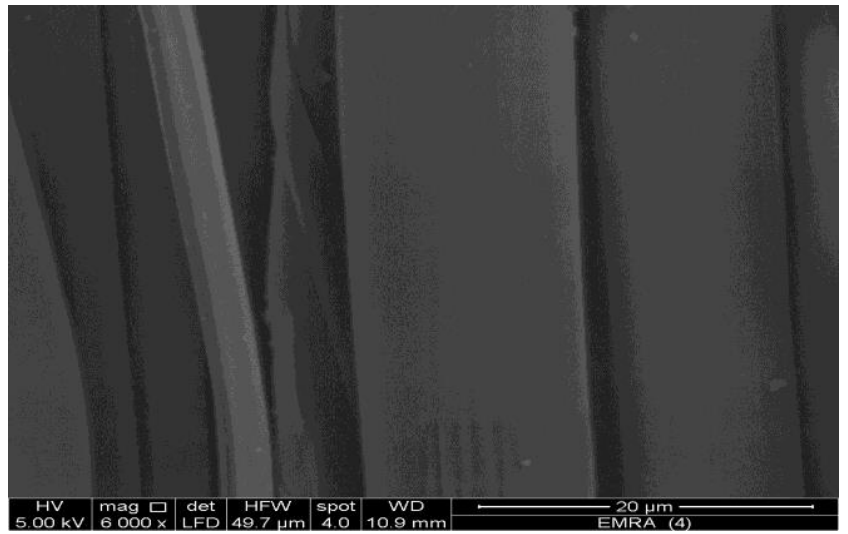

d: Blank Silk

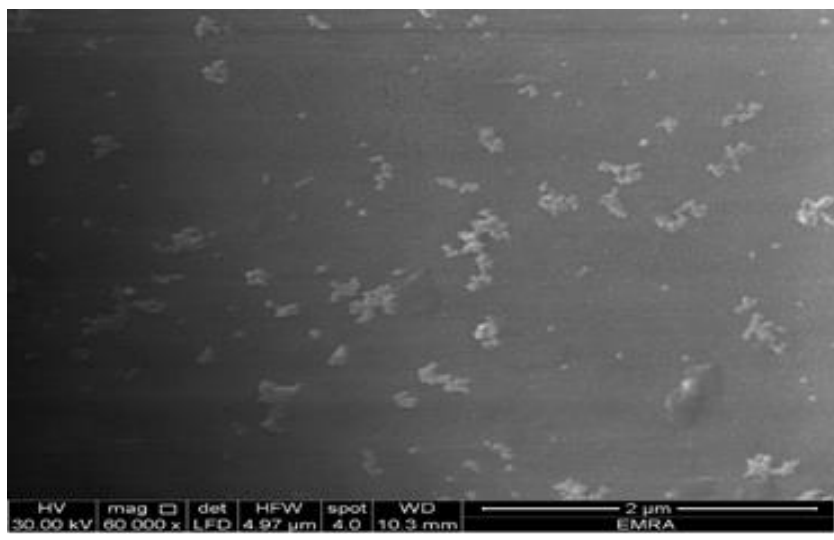

f: Silk exposed to $\mathrm{O}_{2} / \mathrm{Ar}$ mixed gas plasma treated with nano-silver

Fig.8 (a-f) Scanning Electron Microscope (SEM) morphological changes of the samples caused by deposition of silver nano-particles either on polyester or silk samples treated with oxygen/Ar mixed gas plasma 
While SEM images for polyester \& Silk fabrics exposed to O2/Ar plasma treated with nano-silver the plasma exposure of polyester fabrics have no drastic deterioration in the polyester fibers with their swelling and appearance of some nodes on their surface compared to blank untreated one also treatment of polyester fabrics with nano-silver may resulted also in swelling of the fiber surface polyester with the appearance of some nodes on their surface [24].

\subsubsection{Results of antibacterial}

The changes in Antibacterial properties of plasma treated polyester \& silk samples in a medium of oxygen gas using the optimum conditions and $50 \mathrm{ppm}$. nano-silver was shown in Table 4, all examined silk and polyester fabrics was evaluated towards gram negative bacteria (Escherichia coli), and gram positive bacteria (Staphylococcus aureus) after the specified contact time (24h.), where the examined sample were washing and their activity were calculated by measuring inhibition zone against the growth of each bacteria type and the numbers is given in Centimeter. The results indicated that the combination of nano-silver and plasma treatment of polyester and silk fabrics showed very good activity against both type of bacteria by applying low content of nano-silver particles $(50 \mathrm{ppm})$. Using silver nano-particles may lead to increasing the number of particles per unit area on the treated surface and, thus, antibacterial effects can be maximized [33].

Table 4. The changes in Antibacterial properties of different examined plasma treated Silk and polyester samples

\begin{tabular}{|c|c|c|c|}
\hline Fabric & Bacteria name & Blank & $\begin{array}{c}\text { 50ppm. Ag NPs } \\
\text { \& O2/Ar plasma }\end{array}$ \\
\hline \multirow{3}{*}{ Polyester } & $\begin{array}{c}\text { Escherichia coli } \\
\text { (Gram-negative) }\end{array}$ & 0 & 2.3 \\
\cline { 2 - 4 } & $\begin{array}{c}\text { Staphylococcus aureus } \\
\text { (Gram-positive) }\end{array}$ & 0 & 2.1 \\
\hline \multirow{3}{*}{ Silk } & $\begin{array}{c}\text { Escherichia coli } \\
\text { (Gram-negative) }\end{array}$ & 0 & 2.6 \\
\cline { 2 - 4 } & $\begin{array}{c}\text { Staphylococcus aureus } \\
\text { (Gram-positive) }\end{array}$ & 0 & 2.3 \\
\hline
\end{tabular}

Note: Where the examined sample after washing, the numbers are given in Centimeter

\subsection{Dyeing Properties of the Plasma Pretreated Silk Fabric samples}

This part was carried out as an applied part to evaluate the effect of the applied oxygen and oxygen/ argon mixed gas plasma and/or nano-silver treatment on the dyeing properties of selected silk samples under the effect of dye concentrations. These dyeing conditions are applied on the optimized plasma conditions and or nano-silver treatment obtained in the last optimization part, where applied gas is oxygen and oxygen/ argon mixed gas, time is (30) seconds, pressure is (0.3) Torr, and current is (45) m.A.

\subsubsection{Effect of Dye Bath Concentration}

Tables 5 a-e summarize the dyeability expressed as $(\mathrm{K} / \mathrm{S})$ values, color difference $(\Delta \mathrm{E})$ and fastness properties of optimum treated fabrics dyed with natural dye (red lac 25$)$ with concentration dye bath ranges $(0.25,0.5,1.0,1.5$, 
2.0) g./l. Generally, the dye-ability (K/S) value increased by increasing dye concentration for all samples continuously, and this increase was enhanced and/or nano-silver treatment of the fabric samples. Where the improvement of dye-ability by increasing dye concentration resulting from the greater availability of the dye molecules and/or dye radicals in the vicinity of substrates immobile macro radicals, thus increasing dye diffusion and association. On considering the effect of oxygen and oxygen/ argon mixed gas plasma and/or nano-silver treatment on the dyeability (K/S) values. It is clear that the treated fabrics by oxygen/ argon mixed gas have higher $\mathrm{K} / \mathrm{S}$ values and $\Delta \mathrm{E}$ than fabrics treated by oxygen gas Also maximum dyeability was obtained for oxygen/argon plasma and nano-silver treated samples related to their blank dyed mates. Nano-silver work as mordant in case of nano-silver treated samples and also the increased surface area and the modifications of the partition equilibrium of the dye between the dyeing bath and the macromolecular surface in contact with it, can also play a role [13, 14].

Table 5a. Change of dyeing properties for different examined silk samples dyed with $0.25 \mathrm{~g}$. Red lac natural dye

\begin{tabular}{|c|c|c|c|c|c|c|}
\hline \multirow{3}{*}{ Samples } & \multicolumn{3}{|c|}{ Washing Fastness } & \multirow{3}{*}{$\begin{array}{c}\text { Light } \\
\text { Fastness }\end{array}$} & \multirow{3}{*}{$\Delta \mathbf{E}$} & \multirow{3}{*}{$\mathbf{K} / \mathbf{S}$} \\
\hline & \multirow{2}{*}{ Alteration } & \multicolumn{2}{|c|}{ Staining } & & & \\
\hline & & Silk & Cotton & & & \\
\hline Blank Silk & 4 & 4 & 4 & 2 & 20.08 & 0.4160 \\
\hline $\begin{array}{c}\text { Plasma oxygen Treated } \\
\text { Silk }\end{array}$ & $4 / 5$ & $4 / 5$ & $4 / 5$ & $2 / 5$ & 23.79 & 0.5233 \\
\hline $\begin{array}{c}\text { Plasma oxygen } \\
\text { Nano-Treated Silk }\end{array}$ & $4 / 5$ & $4 / 5$ & $4 / 5$ & $2 / 5$ & 27.37 & 0.6606 \\
\hline $\begin{array}{c}\text { Plasma Mixed gas Treated } \\
\text { Silk }\end{array}$ & $4 / 5$ & $4 / 5$ & $4 / 5$ & $2 / 5$ & 30.73 & 0.8241 \\
\hline $\begin{array}{l}\text { Plasma Mixed gas } \\
\text { Nano-.Treated Silk }\end{array}$ & $4 / 5$ & $4 / 5$ & $4 / 5$ & 3 & 32.86 & 0.9624 \\
\hline
\end{tabular}

Table 5b. Change of dyeing properties for different examined silk samples dyed with $0.5 \mathrm{~g}$. Red lac natural dye

\begin{tabular}{|c|c|c|c|c|c|c|}
\hline \multirow{3}{*}{ Samples } & \multicolumn{3}{|c|}{ Washing Fastness } & \multirow{3}{*}{$\begin{array}{c}\text { Light } \\
\text { Fastness }\end{array}$} & \multirow{3}{*}{$\Delta \mathbf{E}$} & \multirow{3}{*}{$\mathbf{K} / \mathbf{S}$} \\
\hline & \multirow{2}{*}{ Alteration } & \multicolumn{2}{|c|}{ Staining } & & & \\
\hline & & Silk & Cotton & & & \\
\hline Blank Silk & 4 & 4 & 4 & 3 & 38.07 & 1.4476 \\
\hline $\begin{array}{c}\text { Plasma oxygen Treated } \\
\text { Silk }\end{array}$ & $4 / 5$ & $4 / 5$ & $4 / 5$ & 3 & 39.06 & 1.5178 \\
\hline $\begin{array}{c}\text { Plasma oxygen } \\
\text { Nano-Treated Silk }\end{array}$ & $4 / 5$ & $4 / 5$ & $4 / 5$ & $3 / 5$ & 40.28 & 1.7168 \\
\hline $\begin{array}{c}\text { Plasma Mixed gas Treated } \\
\text { Silk }\end{array}$ & $4 / 5$ & $4 / 5$ & $4 / 5$ & $3 / 5$ & 40.78 & 1.7844 \\
\hline $\begin{array}{l}\text { Plasma Mixed gas } \\
\text { Nano-.Treated Silk }\end{array}$ & $4 / 5$ & $4 / 5$ & $4 / 5$ & 4 & 41.22 & 1.8623 \\
\hline
\end{tabular}


Table 5c. The change of dyeing properties for different examined silk samples dyed with $1.0 \mathrm{~g}$. Red lac natural dye

\begin{tabular}{|c|c|c|c|c|c|c|}
\hline \multirow{3}{*}{ Samples } & \multicolumn{3}{|c|}{ Washing Fastness } & \multirow{3}{*}{$\begin{array}{c}\text { Light } \\
\text { Fastness }\end{array}$} & \multirow{3}{*}{$\Delta \mathbf{E}$} & \multirow{3}{*}{$\mathbf{K} / \mathbf{S}$} \\
\hline & \multirow{2}{*}{ Alteration } & \multicolumn{2}{|c|}{ Staining } & & & \\
\hline & & Silk & Cotton & & & \\
\hline Blank Silk & $3 / 4$ & 4 & 3 & 4 & 41.14 & 1.8554 \\
\hline $\begin{array}{c}\text { Plasma oxygen Treated } \\
\text { Silk }\end{array}$ & $3 / 4$ & 4 & $3 / 4$ & 4 & 42.24 & 2.0078 \\
\hline $\begin{array}{c}\text { Plasma oxygen } \\
\text { Nano-Treated Silk }\end{array}$ & $4 / 5$ & $4 / 5$ & 4 & 4 & 42.28 & 2.0516 \\
\hline $\begin{array}{c}\text { Plasma Mixed gas Treated } \\
\text { Silk }\end{array}$ & $4 / 5$ & $4 / 5$ & $4 / 5$ & $4 / 5$ & 43.36 & 2.1146 \\
\hline $\begin{array}{l}\text { Plasma Mixed gas } \\
\text { Nano-.Treated Silk }\end{array}$ & $4 / 5$ & $4 / 5$ & $4 / 5$ & $4 / 5$ & 43.78 & 2.3190 \\
\hline
\end{tabular}

Table 5d. Change of dyeing properties for different examined silk samples dyed with $1.50 \mathrm{~g}$. Red lac natural dye

\begin{tabular}{|c|c|c|c|c|c|c|}
\hline \multirow{3}{*}{ Samples } & \multicolumn{3}{|c|}{ Washing Fastness } & \multirow{3}{*}{$\begin{array}{c}\text { Light } \\
\text { Fastness }\end{array}$} & \multirow{3}{*}{$\Delta \mathbf{E}$} & \multirow{3}{*}{$\mathbf{K} / \mathbf{S}$} \\
\hline & \multirow{2}{*}{ Alteration } & \multicolumn{2}{|c|}{ Staining } & & & \\
\hline & & Silk & Cotton & & & \\
\hline Blank Silk & $3 / 4$ & 4 & 3 & 4 & 41.79 & 1.9745 \\
\hline $\begin{array}{c}\text { Plasma oxygen Treated } \\
\text { Silk }\end{array}$ & $3 / 4$ & 4 & $3 / 4$ & 4 & 41.93 & 2.0318 \\
\hline $\begin{array}{c}\text { Plasma oxygen } \\
\text { Nano-Treated Silk }\end{array}$ & 4 & $4 / 5$ & 4 & $4 / 5$ & 43.18 & 2.1146 \\
\hline $\begin{array}{c}\text { Plasma Mixed gas Treated } \\
\text { Silk }\end{array}$ & $4 / 5$ & $4 / 5$ & $4 / 5$ & $4 / 5$ & 44.09 & 2.3669 \\
\hline $\begin{array}{l}\text { Plasma Mixed gas } \\
\text { Nano-.Treated Silk }\end{array}$ & $4 / 5$ & $4 / 5$ & $4 / 5$ & $4 / 5$ & 45.07 & 2.5608 \\
\hline
\end{tabular}

Table 5e. Change of dyeing properties for different examined silk samples dyed with $2.00 \mathrm{~g}$. Red lac natural dye

\begin{tabular}{|c|c|c|c|c|c|c|}
\hline \multirow{3}{*}{ Samples } & \multicolumn{3}{|c|}{ Washing Fastness } & \multirow{3}{*}{$\begin{array}{c}\text { Light } \\
\text { Fastness }\end{array}$} & \multirow{3}{*}{$\Delta \mathbf{E}$} & \multirow{3}{*}{$\mathbf{K} / \mathbf{S}$} \\
\hline & \multirow{2}{*}{ Alteration } & \multicolumn{2}{|c|}{ Staining } & & & \\
\hline & & Silk & Cotton & & & \\
\hline Blank Silk & $3 / 4$ & 4 & 3 & $4 / 5$ & 44.43 & 2.3431 \\
\hline $\begin{array}{c}\text { Plasma oxygen Treated } \\
\text { Silk }\end{array}$ & $3 / 4$ & 4 & $3 / 4$ & $4 / 5$ & 44.96 & 2.5921 \\
\hline $\begin{array}{c}\text { Plasma oxygen } \\
\text { Nano-Treated Silk }\end{array}$ & 4 & $4 / 5$ & 4 & $4 / 5$ & 44.39 & 2.5994 \\
\hline $\begin{array}{c}\text { Plasma Mixed gas Treated } \\
\text { Silk }\end{array}$ & $4 / 5$ & $4 / 5$ & $4 / 5$ & 5 & 45.19 & 2.6607 \\
\hline $\begin{array}{l}\text { Plasma Mixed gas } \\
\text { Nano-.Treated Silk }\end{array}$ & $4 / 5$ & $4 / 5$ & $4 / 5$ & 5 & 45.43 & 2.6692 \\
\hline
\end{tabular}




\subsubsection{Fastness properties for Silk Dyed Plasma Pretreated Samples}

\subsection{2. (a) Washing Fastness}

Washing fastness grades of the examined treated and untreated fabrics samples dyed with natural dye produced at dye bath concentration given in tables 5 (a-e). The obtained results of fastness to washing revealed that for all examined samples, the alteration ranged from fair-good (3-4) for untreated and oxygen plasma treated samples, and excellent (5) for oxygen nano-silver plasma treated, mixed gas plasma Treated and oxygen/argon mixed gas nano-silver plasma treated samples. Staining in general, was small and ranged from slight- no staining (3-4) for untreated, oxygen plasma treated samples, and was no staining (5) for oxygen nano-silver plasma treated, mixed gas plasma Treated and oxygen/argon mixed gas nano-silver plasma treated samples. It is clear that the light fastness grades were improved on oxygen nanosilver plasma treated, mixed gas plasma treated and oxygen/argon mixed gas nano-silver plasma treated samples. Because of increasing the colour strength, the other fastness values were not affected $[13,14]$.

\subsection{2. (b) Light Fastness and Colour Difference Evaluation}

Visual light fastness rating based on the standard Blue Scale were assessed and the obtained results are given in tables 5 (a-e), were showed that the dyed oxygen nano-silver plasma treated, mixed gas plasma Treated and oxygen/argon mixed gas nano-silver plasma treated samples were the highest value (5) with highest colour difference $(\Delta \mathrm{E})$ values. Dyed samples obtained from untreated and oxygen plasma treated their values were of the order $(4-5)[13,14]$.

\subsection{Applied Metrological Part}

\subsubsection{Uncertainty budget of Tensile strength measurement}

There are mainly three sources of uncertainty used to calculate the expanded uncertainty [34]. These sources are:

1. Uncertainty due to repeatability in measurement for $(n)$ times for tensile strength $\left(U_{\text {rep }}\right)$ (Type $\left.A\right)$ and we have repeated the test three times.

2. Uncertainty of Tensile strength tester stated in the calibration certificate ( $\left.U_{\text {tensile }}\right)$ (Type B).

3. Uncertainty due to resolution of Tensile strength tester (Ures.) (Type B).

\section{First part: Uncertainty budget of Tensile strength measurement of polyester samples}

\section{Type A (Uncertainty due to repeatability)}

The uncertainty due to repeatability was calculated for tensile strength values of polyester samples. Where the test was repeated three times so we have three readings, which are tabulated in table 6.

Table 6. Values for Tensile strength in (kgf) of blank polyester samples

\begin{tabular}{|c|c|c|c|}
\hline Sample & 1 & 2 & 3 \\
\hline $\begin{array}{c}\text { T.S of Polyester samples } \\
\text { in (Kgf) }\end{array}$ & 103.2 & 102.6 & 102.5 \\
\hline
\end{tabular}


Average $=102.76$

$$
s=\sqrt{\frac{\sum(X i-\bar{X})^{2}}{n-1}}
$$

$\mathrm{S}($ standard deviation $)=0.378$

Urep $=\mathrm{S} /(\mathrm{n}) 0.5=0.0 .378 /$ (3) $0.5= \pm 0.218$

\section{Uncertainty Type (B)}

I- Uncertainty of Tensile Strength Tester $\left(U_{\text {Tensile }}\right)$

Uncertainty from calibration certificate $=0.0028$,

$\mathrm{U}_{\text {Tensile }}=0.0028 / 2= \pm 0.00144$

$\mathrm{U}_{\text {Tensile }}= \pm 0.0014$

\section{II- Uncertainty due to Resolution of Tensile Strength Tester $\left(U_{\text {res }}\right)$}

$\mathrm{U}_{\text {res }}=0.05 / 1.732050808= \pm 0.0288$

The combined uncertainty for tensile strength values can be calculated as follows;

$U_{c}=\sqrt{U_{R}^{2}+U_{r e f}^{2}+U_{S}^{2}}$

$\mathrm{U}_{\mathrm{C}}=[(0.218) 2+(0.00144) 2+(0.0288) 2] 0.5$

Expanded uncertainty $=0.220 \times 2= \pm 0.440 \mathrm{kgf}$ with confidence level $95 \%$.

The calculations could be summarized in Table 7 .

Table 7. Calculation of uncertainty budget of polyester samples

\begin{tabular}{|c|c|c|}
\hline Source of uncertainty & Probability distribution & $\begin{array}{c}\text { Uncertainty } \\
(\mathbf{\pm \%})\end{array}$ \\
\hline Repeatability & Normal & 0.812 \\
\hline Tensile strength uncertainty & Normal & 0.00212 \\
\hline Resolution & Rectangular & 0.0425 \\
\hline Combined uncertainty & Normal & 0.813 \\
\hline Expanded uncertainty & $\begin{array}{c}\text { Normal } \\
(\mathrm{K}=2)\end{array}$ & 1.626 \\
\hline
\end{tabular}

\section{Second part: Uncertainty budget of Tensile strength measurement of silk samples}

\section{Type A (Uncertainty due to repeatability)}

The uncertainty due to repeatability was calculated for tensile strength values of silk sample. As we mention before, the test was repeated three times so we have three readings, which are tabulated in table 8. 
Table 8. Values for tensile strength of blank silk samples

\begin{tabular}{|c|c|c|c|}
\hline Sample & 1 & 2 & 3 \\
\hline $\begin{array}{c}\text { T.S of silk } \\
\text { samples in (Kgf) }\end{array}$ & 67.9 & 66.8 & 68.7 \\
\hline
\end{tabular}

Average $=67.8$

$s=\sqrt{\frac{\sum(X i-\bar{X})^{2}}{n-1}}$

$\mathrm{S}($ standard deviation $)=0.95$

$\mathrm{U}_{\text {rep }}=\mathrm{S} /(\mathrm{n}) 0.5=0.95 /$ (3) $0.5= \pm 0.550$

\section{Uncertainty Type B}

\section{I- Uncertainty of Tensile Strength Tester $\left(U_{\text {Tensile }}\right)$}

Uncertainty from calibration certificate $=0.0028$,

$\mathrm{U}_{\text {Tensile }}=0.0028 / 2= \pm 0.00144$

$\mathrm{U}_{\text {Tensile }}= \pm 0.00144$

II- Uncertainty due to Resolution of Tensile Strength Tester $\left(U_{r e s}\right)$

$\mathrm{U}_{\text {res }}=0.05 / 1.732050808= \pm 0.028 \%$

Then combined uncertainty for tensile strength values can be calculated as follows;

$U_{c}=\sqrt{U_{R}^{2}+U_{r e f}^{2}+U_{S}^{2}}$

$\mathrm{C}=[(0.550) 2+(0.00144) 2+(0.028) 2] 0.5$

Expanded uncertainty $=0.551 \times 2= \pm 1.103 \mathrm{kfg}$, with confidence level $95 \%$.

The calculations could be summarized in Table 9 .

Table 9. Calculation of uncertainty budget of silk samples

\begin{tabular}{|c|c|c|}
\hline Source of uncertainty & Probability distribution & $\begin{array}{c}\text { Uncertainty } \\
\mathbf{( \pm \% )}\end{array}$ \\
\hline Repeatability & Normal & 0.812 \\
\hline Tensile strength uncertainty & Normal & 0.00212 \\
\hline Resolution & Rectangular & 0.0425 \\
\hline Combined uncertainty & Normal & 0.813 \\
\hline Expanded uncertainty & Normal $(\mathrm{K}=2)$ & 1.626 \\
\hline
\end{tabular}




\subsubsection{Traceability}

Tensile Strength Tester used in carrying out the test was calibrated using primary standards kept in the National institute of Standards (NIS-Egypt) where all the measurements were traceable to SI units [35]. Tensile Strength tester depends in his work on a load cell 5000 Newton capacity, it was calibrated in Force and Material Metrology Lab. In the National Institute of Standards (NIS-Egypt) with certificate number 661/14/2020. The environmental condition must be monitored before and during the test using calibrated data logger, it was calibrated in Thermal Metrology Lab. In the National Institute of Standards (NIS-Egypt) with certificate number 1451/32/2020.

\section{Conclusions}

In this article we evaluate the effect of treated silk and polyester fabrics using plasma oxygen/argon mixed gas and/or nano silver on mechanical properties, UPF and air permeability. The results showed that UPF values increase for both exposed fabrics but the increase is not significant in silk fabrics, results of mechanical properties confirm that plasma treatments can be used on silk yarn without significant adverse effect on the physical properties of the fibers, while for treated polyester it increases up to $30 \mathrm{sec}$ and increase by increasing exposed current and pressure up to 0.3 torr. Air permeability properties increase for treated silk fabric by increasing time, current and pressure of exposed but for treated polyester fabrics it increases up to $45 \mathrm{sec}$. time exposed, current $45 \mathrm{~m}$.A.and up to 0.3 torr of pressure. The SEM images showed that plasma and or nano silver treatment of polyester and silk fabrics increase in roughness of surface due to the etching effect of plasma, also SEM images show that the interaction between the fabrics and the silver nano-metal results from plasma physical effect on the fabric surface. Finally, antibacterial properties were highly improved by the treatment of fabrics that verify one of the main goals of this research.

\section{Declarations}

\section{Source of Funding}

This research did not receive any grant from funding agencies in the public, commercial, or not-for-profit sectors. Competing Interests Statement

The authors declare no competing financial, professional and personal interests.

\section{Consent for publication}

Authors declare that they consented for the publication of this research work.

\section{References}

[1] U. Choudhary, E. Dey, R. Bhattacharyya and S. K. Ghosh, A brief review on plasma treatment of textile materials, Advance Research in Textile Engineering, 3(1) (2018).

[2] S. Kryštofová, Šimončicová, V. Medvecká, K. Ďurišová \& B. Kaliňáková, Technical applications of plasma treatments: current state and perspectives Juliana, Applied Microbiology and Biotechnology, 103 (2019), 5117-5129. 
Middle East Journal of Applied Science \& Technology

Vol.4, Iss.4, Pages 80-103, October-December 2021

[3] A. Pars, R. Karadag, M. S. Ozen \& E. Sancak, The Effect of Laser Radiation in Different Mordant and Ratios on Silk Fabrics Dyed with Weld (Reseda luteola L.), Journal of Natural Fibers, 11 (2021).

[4] L. Decandra, The effect of plasma treatment on the dyeability of silk fabric by using Phytolacca natural dye extract, Tekstil ve Konfeksiyon, 26(3) (2016), 262-269.

[5] H.M.El-Hennawi, S.A.Mahmoud, A.A Ragheb. Eco-friendly coloration of silk and flax fabrics with natural dye enhanced by ultraviolet radiation. Egypt Pharmaceutical Journal, 16(3) (2017), 192-198.

[6] J. Loum, R. Byamukama, P.Wanyama, Application of natural dyes from selected indigenous plants on cotton and silk fabrics. Journal Textile Engineering Fashion \& Technology, 7(2) (2021), 71-77.

[7] A. Talebian, S. Habibi \& P. Neshat, Green dyeing of weld on corona discharge treated wool fabric, The Journal of The Textile Institute, 112(1) (2021), 144-151.

[8] P. Kongkachuichaya, A. Shitangkoonb and N. Chinwongamorna, Studies on Dyeing of Silk Yarn with Lac Dye: Effects of Mordants and Dyeing Conditions, Science Asia 28 (2002), 161-166.

[9] B. Y. Şahinbaşkan, R. Karadag \& E. Torgan, Dyeing of silk fabric with natural dyes extracted from cochineal (Dactylopius coccus Costa) and gall oak (Quercus infectoria Olivier), Journal of Natural Fibers, 15(4) (2018), $559-574$.

[10] J. Sheikh, S. Priyanka Jagtap \& M. D. Teli, Ultrasound Assisted Extraction of Natural Dyes and Natural Mordants vis a vis Dyeing, Fibers and Polymers, 17(5) (2016), 738-743.

[11] O. Deveoglu \& R. Karadag, A review on the flavonoids-a dye source. International Journal of Advances in Engineering and Pure Sciences, 31(3) (2019), 188-200.

[12] P. Abdulkadir, The Effect of Laser Radiation in Different Mordant and Ratios on Silk Fabrics Dyed with Weld (Reseda luteola L.), Journal of Natural Fibers, (2021), 1-15.

[13] D. M. Essa, S. F. Ibrahim, Khaled Elnagar, Ahmed M. Abdel-Razik \& Adel A. H. Abdel-Rahman, Characterization and evaluation of polyester and silk fabrics treated using plasma as clean energy advanced technique, Egyptian Journal of Chemistry, 62 (2019), 75-90.

[14] M. Bafoil, A. Jemmat, Y. Martinez, N.Merbahi, O.Eichwald, C.Dunand, M.Yousfi, Effects of low temperature plasmas and plasma activated waters on Arabidopsis thaliana germination and growth. PLoS One, 13 (2018), 1-16.

[15] S.S. Salem, E.F. El-Belely, G. Niedbała, M.M. Alnoman, S.E.D. Hassan, A.M. Eid \& A. Fouda, Bactericidal and in-vitro cytotoxic efficacy of silver nanoparticles (Ag-NPs) fabricated by endophytic actinomycetes and their use as coating for the textile fabrics, Nanomaterials, 10(10) (2020).

[16] R. Mia, M.S. Sk, Z.B.S. Oli, T. Ahmed, S. Kabir \& M.A. Waqar, Functionalizing cotton fabrics through herbally synthesized nanosilver, Journal of Cleaner Engineering and Technology, 4 (2021).

[17] A. Ado, H. Yahaya, A.A. Kwalli, \& R.S. Abdulkadir, Dyeing of textiles with eco-friendly natural dyes: a review. International Journal of Environmental Monitoring and Protection, 1(5) (2014), 76-81. 
[18] Standard Test Method, ASTM D737 - 04 (2016).

[19] Standard Test Method for Breaking Force and Elongation of Textile Fabrics (Strip Method), ASTM D5035 -11 (2019).

[20] S.F. Ibrahim, D.M. Essa, A.M. Abdel-Razik, K.H. Elnagar, M.A. Saudy \& A.H.Abdel-Rahman, Application of DC plasma discharge and/or nanosilver treatments to poly ethylene terephthalate fabrics to induce hydrophilicity and antibacterial activity, Elixir Appl. Chem., 50 (2012), 10370-10377.

[21] J. Shao, C.M. Carr, C.P. Rowlands \& J. Walton, XPS, SIMS, and ESR studies of UV/ozone-irradiated silk and wool, Journal of Textile Institute, 90(4) (1999 ), 459-468.

[22] H. Deng, B. Deng \& C. Xiao, Nano-materials in UV protection textiles, Textile Asia, 6 (2007), 40-42.

[23] S.F. Ibrahim, D.M. Essa \& E.M. Osman, Spectral evaluation studies on titanium dioxide nano-particles and their add-mixtures on textile fabrics, Egyptian Journal of Chemistry, 59(6) (2016), 1069 -1093.

[24] Q. Wei, X. Wang, R.M, Rhodes \& A. Fotheringham, New approaches to characterization of textile materials using environmental scanning electron microscope, Fibres \& Textiles in Eastern Europe, 12 (2004), 79-83.

[25] P. Brun P, G. Bernabè, C. Marchiori, M. Scarpa, M. Zuin, R. Cavazzana, B. Zaniol, E. Martines, Antibacterial efficacy and mechanisms of action of low power atmospheric pressure cold plasma: membrane permeability, biofilm penetration and antimicrobial sensitization, Journal of Applied Microbiology, 125 (2018), 398-408.

[26] S.F. Ibrahim, M.N. Michael and F.M. Tera, Characterization of dye-ability and diffusion kinetics of chemically modified cotton fabrics towards disperse and direct dyes, International Journal of Advanced Research in Chemical Science, 3(5) (2016), 7-16.

[27] ISO 105-C06: Textiles-Tests for colour fastness, (2010).

[28] ASTM, G 23, (1996).

[29] R.M. Wafaa, S.R. Usama, E.S. Hanan \& E. A. Azza, Ultraviolet protection, flame retardancy and antibacterial properties of treated polyester fabric using plasma-nano technology, Mat. Sci. \& Appl., 2 (2011), 1432-1442.

[30] S.F. Ibrahim, D. M. Essa, A.M. Abdel-Razik, K.H. Elnagar, M.A. Saudy \& A.H. Abdel-Rahman, Application of DC plasma discharge and/or Nanosilver treatments to poly ethylene terephthalate fabrics to induce Hydrophilicity and antibacterial activity, Elixir Appl. Chem., 50 (2012), 10370-10377.

[31] H.U. Poll, U. Schladitz \& S. Schreiter, Penetration of plasma effects into textile structures, Journal of Surface Coating and Technol., (2001), 489-493.

[32] M.O.H. Cioffi, H.J.C. Voorwald, V. Ambrogi, T. Monetta, F. Bellucci \& L. Nicolais, Mechanical strength of PET fibers treated in cold plasma and thermal exposed, Journal of Material Engineering Perform, 12 (2003), 279-287.

[33] K.H. El-Nagar, M.A. Saudy, A.I. Eatah \& M.M. Masoud, DC pseudo plasma discharge treatment of polyester textile surface for disperse dyeing, Journal of Textile Institute, 97(2) (2006), 111-117. 
Middle East Journal of Applied Science \& Technology Vol.4, Iss.4, Pages 80-103, October-December 2021

[34] Farrance R. Frenkel, Uncertainty of measurement: A review of the rules for calculating uncertainty components through functional relationships, Clin Biochem Rev., 33(2) (2012), 49-75.

[35] J.D.B. Paul, T. Philip, Traceability to the SI of amount-of-substance measurements: From ignoring to realizing, a chemist's view, Metrologia, 34(1) (2003), 67p. 